\title{
STUDY ON THE DISTRIBUTION OF SEISMIC INTENSITY OF THE 1855 ANSEI EDO EARTHQUAKE IN THE KANTO DISTRICT
}

\author{
By Takahisa ENOMOTO*
}

\begin{abstract}
The epicenter of the Ansei Edo Earthquake $(M=6.9)$ which occurred on llth November of 1855 was situated in the vicinity of Edo (present-day Tokyo) and much destruction was caused in the urban area of Edo and the nearby towns in Kanto District. In this paper, I have investigated the damages caused by Ansei Edo Earthquake on the basis of various old documents of the time in which the heavy damage is described and have determined the distribution of the damage and the seismic intensity (M. S. K Scale) in Kanto District.

Also, I have computed the intensity of this earthquake theoretically at many sites situated in the Kanto District, by using several fault models and taking the geological condition in the Kanto District into account.

Keywords : Ansei Edo Earthquake, seismic intensity
\end{abstract}

\section{INTRODUCTION}

One of the most important points in studying disaster prevention, especially concerning seismic disasters, is a basic understandings of the characteristics and the regional difference of incident seismic wave. In the near future, this understanding will progress and increase remarkably by means of the accumulated data concerning the mechanism of seismic generation and the observation records of various seismic waves. It is also true that the recorded examples of actual damage (damaged houses, liquefaction, overturning tobmstones etc.) caused by the historical great earthquakes offer most valuable information, which is different from the direct measurement by seismic waves in the specific area which have suffered great damage from earthquake.

Therefore, the investigation of damage caused by historical great earthquakes is very important and it is necessary that the seismic wave characteristics concerning the destruction caused be considered synthetically by utilizing the rapidly expanding knowledge of seismology.

Also, this kind of study for disaster prevention in urban areas from the point of view of formulating policy. In this paper, I have investigated the distribution of many cases of damage and seismic intensity (M. S. K Scale) that occured by the 1855 Ansei Edo Earthquake in the Kanto District, taking into account current seismological knowledge. Especially, in this paper, I determined the distribution of damage in detail in the urban area of Edo at many stages along the old roads and in many neighbouring villages, then from results I tried to estimate the distribution of seismic intensity covering the alomst all of the Kanto District. Recently, in the Kanto District, the micro-seismic observation system has been implemented, and based on its observed results, an unified model of the tectonics concerned the Kanto and Tokai District

* Meber of JSCE, M. Eng. , Kanagawa University, Research Associate

(3-27-1 Rokkakubashi Kanagawa-ku Yokohama-shi 221) 
has been proposed" and this has been established as the commonly recognized mechanism of seismic generation. Also it has been suggested that the mechanism of seismic generation concerning the 1855 Ansei Edo Earthquake happened at the intersection of two tectonic plates-Philippine Sea Plate and Asian Plate ${ }^{2)}$. In this paper, I have made a theoretical analysis based on the theoretical computation method using the fault model and assumed underground structure model referring to the results of research on underground and basement structure covering the Kanto District which have been carried out heretofore. Then, I tried to compare the theoretical result with the investigated result as evaluated from the actual damage. I think that in the future these results will provide the basic and valuable information for formulating policy for seismic disaster prevention and the study of seismic wave characteristics.

The basical and general flow of this study is shown in Fig. 1

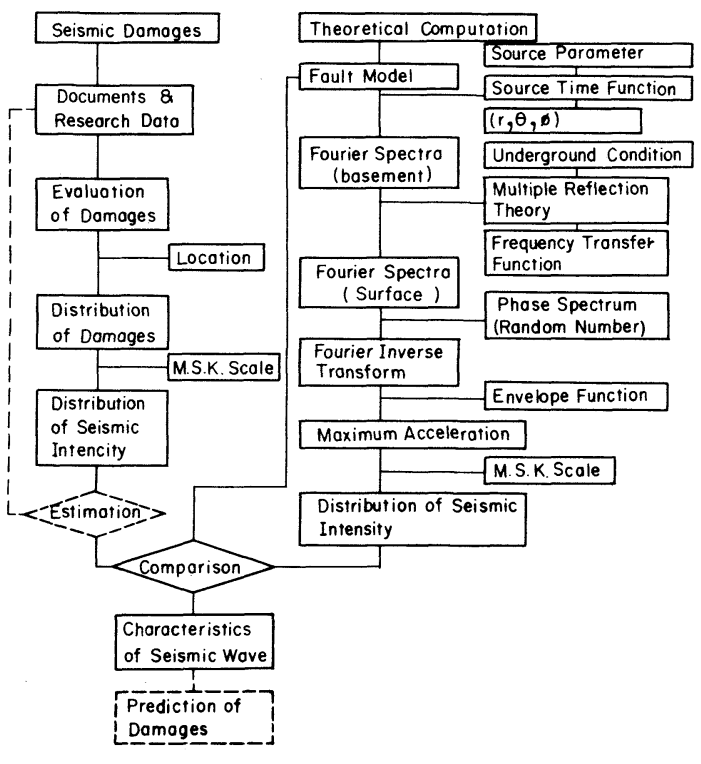

Fig. 1 General flow of the study.

\section{SUMMARY OF PAST STUDIES OF THE ANSEI EDO EARTHQUAKE}

The summary of the past studies of the 1855 Ansei Edo Earthquake is described as follows. The Ansei Edo Earthquake happened at about 10 p. m. on 11 th November, 1855. It was a middle-scale earthquake and the hypocenter was situated inland at a place directly under the present Tokyo Metropolis. It was thought that the magnitude of this earthquake was 6.9 and the location of the hypocenter was assumed to be at the mouth of the Ara River and its vicinity and that the seismic fault nearly coincided with a line which connected Kameido and Kameari. Also, it was assumed that the focal depth was from $30 \mathrm{~km}$ to $50 \mathrm{~km}$ deep. In the then city of Edo in the last stage of the Edo era in the second half of 19th century, the population was about $1,300,000$ persons and the city constituted a very large urban area and was divided into three zones-the zone of samurais, the zone of temples and the zone of artisans. Center of the urban area was the castle of $\mathrm{Edo}^{3}$. It has been investigated and reported that the damages caused by this earthquake was very great. For example, the number of houses destroyed by the quake and by five fires totaled 1436, some 4, 000 people were killed in the artisan zone, fire broke out in about 30 places and the burn down area was about 2.3 square kilometers, and very heavy damage was caused in the urban area of Edo City and its vicinity ${ }^{4)}$.

Recently, Dr. M. Sayama investigated the damage caused by the Ansei Edo Earthquake ${ }^{5)}$. He has examined minutely the distribution of destruction in the old area of Tokyo city from old documents describing the damage, and he has indicated the distribution of seismic intensity using the international seismic intensity scale (M. S. K Intensity Scale) in the urban area of Edo city. Also he has examined the location of fire outbreaks, area burnt down and the distribution of death. Dr. T. Mochizuki et al also investigated the destruction paying attention to the damage to wooden houses called Machiya in the city of $\mathrm{Edo}^{6}$. From the results of the above investigations, they pointed out that the damage caused by this earthquake was not always affected by the simple difference of the ground condition, but also, most remarkably, by the distance from the hypocenter.

Dr. T. Usami has investigated the distribution of seismic intensity using the J. M. A Intensity Scale at 
many places in the Edo city and its vicinity by referring to many old documents. On the basis of this, he has shown the assumed distribution of seismic intensity covering the Kanto District. In addition, Dr. H. Takahashi et al have constructed a global tectonic model covering the Kanto District and the Tokai District from the results recorded by the micro-seismic observation system and they have pointed out that the Ansei Edo Earthquake was very likely due to the inter-plate activity at the boundary between the upper plane of the Phailippine Sea plate and the Asian plate which is taken to be the most typical mechanism of seismic generation in the Kanto District ${ }^{1 / 2)}$.

\section{DISTRIBUTION OF DAMAGE AND SEISMIC INTENSITY IN EDO CITY}

The urban area of the past Edo at the time of Ansei 2 (1855) constituted three zones as before mentioned, and the city was bounded by Honjo and Fukagawa on the east, Yotsuyaookido and Itabashi on the west, Shinagawa to be south and Senju to be north ${ }^{3}$. The samurais area was the largest and the wooden houses of samurai were extensively distributed in the zone but there were many poor houses of tradesmen densely crowded together in the artisan zone.

The classification of zoning covering the above mentioned area is indicated in detail in "a map on land utilization in Edo" drawn up by Dr. T. Masai ${ }^{8}$. In addition, a detailed area map of Edo city “Map of Edo" was published and used generally by many people ${ }^{9}$. By means of this map the names of Edo districts and the exact location of higher, middle and lower grade residences of daimyos (feudal lord), general houses of samurais, temples and shrines were confirmed in detail. Thus it was possible to pinpoint the exact locations of towns, residences, houses and temples etc. based on the proper names described in the old documents concerning the damage caused by the Ansei Edo Earthquake.

By using the two kinds maps in this paper, I investigated the distribution of damage in Edo city and its vicinity in detail by referring to the many documents on the damage of the Ansei Edo Earthquake and some other newly collected documents which were found subsequently. The extent of damage was classified roughly into five classes based on the documents'description of damage to houses, godowns, gates, walls and embankments.

The five classes are shown below.

\section{Class Classification}

1. Completely destruction

2. Heavy damage

3. Medium damage

4. Slight damage

5. No damage

\section{Descripton of damage}

All or almost all structures destroyed, destroyed

Here and there destroyed, most structures damaged

Half destroyed, here and there damaged

Few structures damaged

No structures damaged

The above classifications were created on the basis of the extent of damage, the is to say, class 1 was the situation where more than $50 \%$ of houses were destroyed and almost $100 \%$ of houses or structures were damaged, class 2 was where about $30 \%$ of houses were destroyed and about $50 \%$ of houses or structures damaged, class 3 was where about $10 \%$ of houses were destroyed and about $30 \%$ of houses or structures damaged and class 4 was where about $10 \%$ of houses were damaged. According to the above classification I tried to recognize the exact location of the damaged structures on the "Map of Edo" and marked it with symbols corresponding to the damage described in the documents used in this paper. And then, finally I tried to complete picture of the distribution of the damage by using all documents, estimating the classification and judging synthetically. After that, the final map of the damage distribution was completed by superposing the above result on "the map of urban land use" and the locations of damaged structures indicated in the "Map of Edo" were thus determined. The final map of the distribution of damage is shown in Fig. 2. Also the result of study of burnt down areas using the same method mentioned above is shown in Fig. 3. From these results, the seismic intensity (12 classes) of this earthquake at each region was evaluated based on the damage distribution and using the international seismic intensity scale (M. S. K 


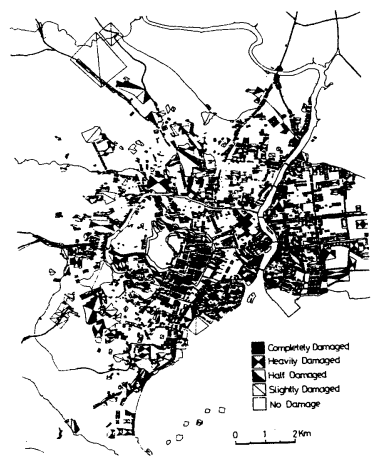

Fig. 2 Distribution of the damage in urban area of Edo (Tokyo).

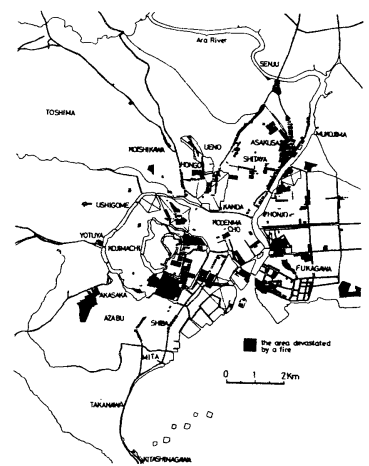

Fig. 3 Distribution of the area devasted by a fire in Edo (Tokyo).

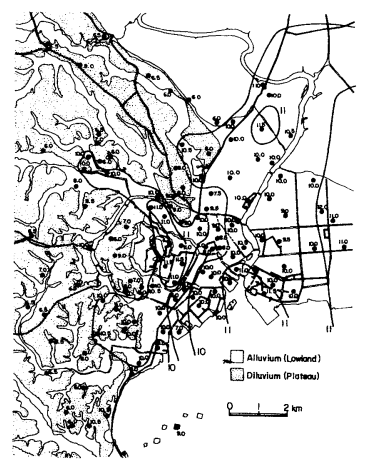

Fig. 4 Distribution of the seismic intensity (M. S. K Scale) in Edo (Tokyo).

Intensity Scale) which was used in the study by Dr. M. Sayama. The result of the estimated seismic intensity is shown in Fig. 4.

Referring to the result, there are clear differences of seismic intensity distributed in Edo city, that is to say, the seismic intensity in the low-lying part was higher than that of the western part where the land elevation was higher, and also in the low-lying land there was a tendency for higher seismic intensity to spread to the more eastern part located near the boundary of Chiba Prefecture. Also, according to the distribution of seismic intensity, a tendency was noted of a little higher seismic intensity than previously estimated for the region form Marunouchi to Mita along the Tokaido Road.

\section{DISTRIBUTION OF SEISMIC INTENSITY IN THE KANTO DISTRICT}

It is very difficult to evaluate exactly the distribution of the seismic intensity in the Kanto District at the time of the Ansei Edo earthquake because there are relatively few documents describing the circumstances and the distribution of the damage. However, after the earthquake, the shogunate commanded the local governor's office to survey and make a report of the circumstances of damage to houses, godowns and the death rate etc. in the stage towns and villages in the controlled area. These reports concerning to Tokyo

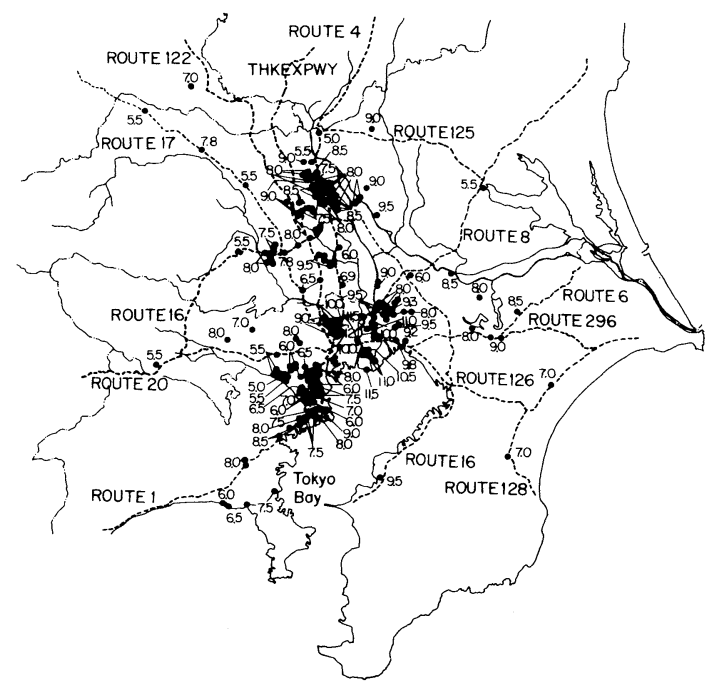

Fig. 5 Distribution of the seismic intensity (M. S. K Scale) in the Kanto District.

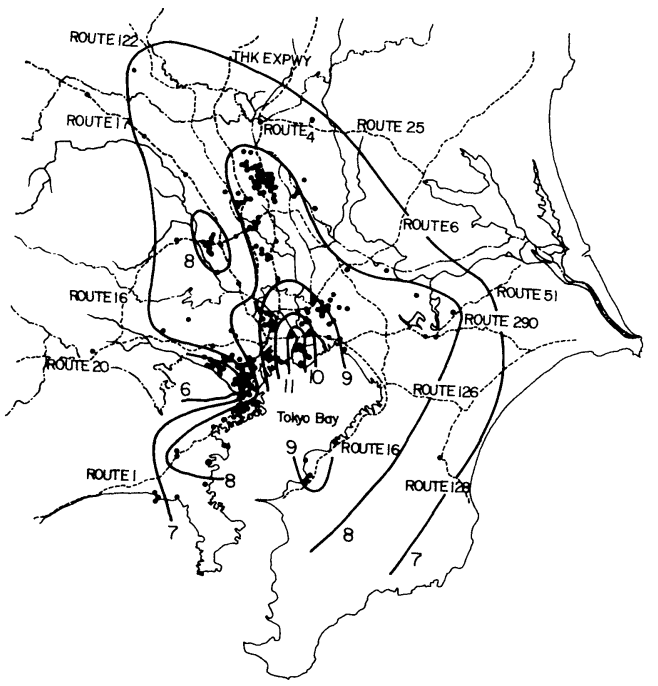

Fig. 6 Iso-seismal map in the Kanto District. 
Metropolics, Saitama Prefecture, Kanagawa Prefecture, Chiba Prefecture and the some portion of Ibaragi Prefecture have been reserved. In this paper, based on these documents including newly found data, the classification of damage was estimated by using the same method as that used to classify the grades of damage in the Edo city and the seismic intensity at each location in the Kanto District were evaluated by the international seismic intensity scale. Moreover, the past location of each stage town or village was confirmed exactly from the document called "Musashi-koku Shinpen Fudokiko"10) and then the location was plotted on the map. The result is shown in Fig. 5. From the result, it was possible to newly evaluate. The distribution of seismic intensity at the stage towns and many villages along the Oshu, Nikko, Nakasendo, Mito and Tokaido Road int he Kanto District and then it was also possible to make clear the distribution of seismic intensity in the relatively wide region of the Kanto District. The resulting isoseismal line in the Kanto District evaluated by the above mentioned result using the international seismic intensity scale is shown in Fig. 6.

\section{GEOGRAPHICAL FEATURES AND GROUND CONDITION IN THE KANTO DIS- TRICT}

Generally the strata of the Quaternary Period and the geographical features of terracing are widely spread in the Kanto District including the Tokyo metropolis and its vicinity ${ }^{11}$. It has already been shown that is particular, the thickness of soft strata constituted in in Quaternary Period covering the plains of Kanto had piled up very deeply. These investigations concerning the geographical and geological features of the Kanto District ${ }^{12)}$ have been developed up to this time and a summary of these results is shown in Fig. 7. According to the contour line of the bottom basement strata of the Quaternary Period (See Fig. 9) described by Dr. T. Kakimi et al., the distribution of the depth of the piled up layer in the Quaternary Period is very clear and it was recognized that the deepest layer had piled up at Chiba city and its vicinity located at the inner part of Tokyo Bay to a depth of about 1,400 m. Also, it has been recognized that a large scale tray-like geological structure extends north-west from Chiba city to Maebashi and Takasaki city. Also it showed the contour line of the basement depth along the basins of the Ara river and Edo River extended northwest at from $600 \mathrm{~m}$ to $800 \mathrm{~m}$ deep. The seismic basement rock constituted before the Tertiary Period which exists under the later. Tertiary strata constitutes the geographical condition called hilly country or hilly district found at Miura Peninsula and the southern part of Boso Peninsula in the southern part of Kanto District, and also the Quaternary Strata constituting the surface layer in the Kanto District goes very deep underground in the Kanto Plains. This basement rock is spread very widely as the basement strata of the Kanto District and it is thought that the basement rock corresponds to the seismic basement ${ }^{11)}$. Now the physical measurements were advanced very vigorously in order to determine the underground condition including the seismic basement rock, but the bottom basement contour line of the newly Tertiary Strata has already been shown by geographical and geological survey. According to the result, the depth of the layer to the basement rock was about $4,000 \mathrm{~m}$ at the deepest region ${ }^{11}$.

\section{UNDERGROUND CONDITION OF THE KANTO DISTRICT}

Recently, many investigations of the underground condition covering the Kanto District have been done by the physical research method which is one of the most direct methods for this kind of

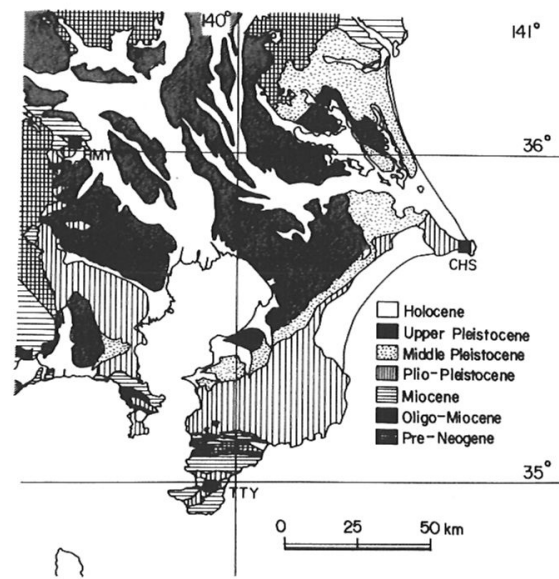

Fig. 7 geological features in the Kanto District. 


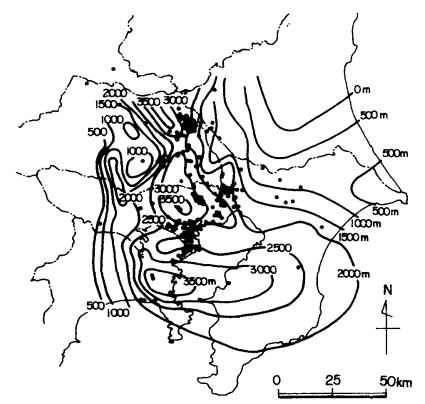

Fig. 8 Contour line of the seismological basement in the Kanto District.

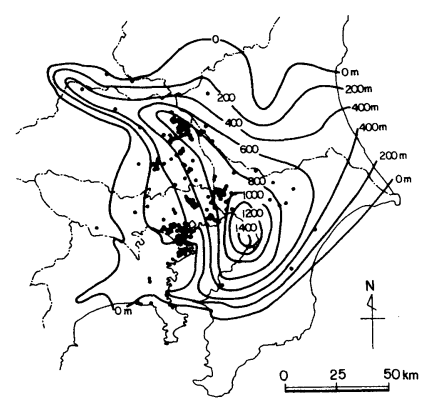

Fig. 9 Contour line of the base for Quatenary Period.

investigations concerned with the seismological, geographical and geological approach. Especially, by means of deep boring, the research of underground conditions by measuring the artificial seismic wave generated by explosion ${ }^{13)}$, and by gravity measurement ${ }^{14)}$ in the Kanto District, information concerning the basement structure has been gathered for the almost all regions in the Kanto District. At the sited of deep boring and on the measurement lines of the research of underground conditions by artificial seismic waves generated by explosion, the physical condition and many constants concerning the underground structure were estimated.

In this paper, rearranging these past investigate results generally and referring to the contour lines of the bottom basement of the Quaternary and Tertiary Strata according to the geological period division, the underground condition was summarized and also an accurate map for bouge abnormality ${ }^{15)}$, compiled separately was used for the information showing the plane contour line of bottom basement. The contour lines of the seismological basement (basement rock of which $S$ wave velocity $\left(V_{s}\right)$ was about $3.0 \mathrm{~km} / \mathrm{s}$ and $\mathrm{P}$ wave velocity $\left(V_{p}\right)$ was about $6.0 \mathrm{~km} / \mathrm{s}$ ) estimated by the above results is shown in Fig. 8 . Then, as to the upper part of underground condition on the seismological basement, referring to the geological bottom basement of Quatenary Strata described by Dr. T. Kakimi et al., the contour lines are shown in Fig. 9.

\section{CALCULATION OF SEISMIC INTENSITY BY THE FAULT MODEL}

In this paper the analytical investigation has been done by the theoretical computation method using a fault model in order to study the hypocenter and the distribution of seismic intensity. The fault model used in this paper was the model developed by Dr. N. A. Haskell shown in Fig. 10 and the Fourier Spectra of acceleration of $\mathrm{S}$-wave was computed by the following expressions ${ }^{16) \sim 18)}$.

$$
\begin{aligned}
& \ddot{U}(\omega)=M_{0} \cdot R(\theta, \phi, r) \cdot\left\{G(\omega) \cdot \omega^{2}\right\} \cdot\{F(\omega, \xi) \cdot \omega\} \cdot \exp \left(\frac{-\omega r}{2 Q \beta}\right) \\
& \mid \mathbf{R}(\theta, \phi, r)=\frac{\mathbf{e}_{\theta} \cdot \cos 2 \theta \cdot \sin \phi+\mathbf{e}_{\phi} \cos \theta \cdot \cos \phi}{4 \pi \beta^{3} \rho r}
\end{aligned}
$$

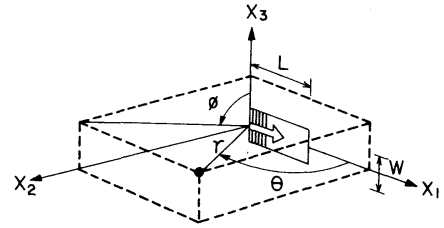

Fig. 10 Seismic fault model.

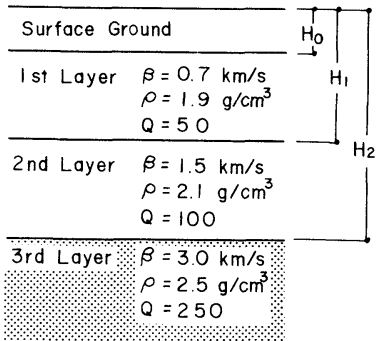

Fig. 11 General condition of multi-layered ground model in the Kanto District. 


$$
\left\{\begin{array}{l}
F(\omega, \xi)=\frac{\sin (\omega \xi / 2)}{(\omega \xi / 2)} \ldots \\
\xi=L \cdot\{(\beta / V)-\cos \theta\} \beta
\end{array}\right.
$$

Where, $M_{0}$ is the seismic moment, $\beta$ is the $\mathrm{S}$-wave velocity of the media, $\rho$ is the density of media, $Q$ is the damping factor, $V$ is the propagating rupture velocity and also $G(\omega)$ is the Fourier Transform of source time function $g(t)$. $\mathbf{e}_{\theta}$ and $\mathbf{e}_{\phi}$ are the unit vectors.

For the underground condition at each site whose spectra had to be computed in the Kanto District the three horizontally layered models shown in Fig. 11 were assumed, referring to the Fig. 8 and Fig. 9. These three layered models were taken to be based on the contour lines concerning the Quaternary Strata and seismological basement rock described before. It was also very important to think about the circumstances of the surface ground condition below the several tens of meters from the ground surface in the case of consideration of the seismic wave characteristics. In this paper, the circumstances of the surface ground condition were evaluated by classification of the detailed geographical features of each site surface shown in Table 1. On the other hand, by using Haskell's fault model, the seismic wave spectrum at the basement level (corresponding to the seismological basement) was computed by expression (1) for any site. So the spectrum characteristics at ground surface was computed by considering the frequency transmission function estimated by the underground condition. The computation was done by the three types of source-time functions $g(t)$ concerning the fault as shown in Fig. 12 .

Now, the tendency and the computation result of the seismic wave spectrum at the basement evaluated by above mentioned fault model has been investigated. Assuming the magnitude at $M=7.0$ and setting the fault parameters based on experimental expression provided by the magnitude $M$, some examples of seismic wave spectra at any site calculated by changing the $(\theta, \phi, r)$ which describes the relative position between the hypocenter and any site, are shown in Fig. 13. In Fig. 13, it was assumed that $r=50 \mathrm{~km}, \theta=$ $0^{\circ} \sim 180^{\circ}$ and $\phi=50^{\circ}$ (refer to Fig. 10).

Now, (a) showed the Type A of soure time function, (b) showed the Type B and (c) showed the Type C. Referring to Fig.13, the characteristics of calculated spectra differ from each other according to each parameter. The result for the maximum value of the spectral amplitude $\ddot{U}(\omega)$ described by the corresponding parameter of $(\theta, \phi, r)$ is shown in Fig. 14. This result corresponds to the directional distribution of the amplitude.

Referring to Fig. 14, it was recognized clearly that the maximum value of the spectral amplitude varied according to the values of parameter $\theta$ and $\phi$. In the three types of source time functions assumed in this paper, the case of Type $C$ showed the largest value of the maximum spectral amplitude. Anyway, including the consideration of the more complex source mechanism, the selection of these types for source time function is concerned with the mechanism of seismic generation (the formation of rupture propagation on the fault plane) and it is very difficult to decide the source mechanism when there are no seismic records because it will be different for each earthquake. Then it becomes very important to solve the problem by analyzing the observed seismographic readings for the same region, in the future.

Table 1 Assumed conditon of surface ground model.

\begin{tabular}{|c|c|c|c|c|}
\hline \begin{tabular}{|c|} 
Micro Geographical \\
Feotures
\end{tabular} & $\begin{array}{c}\text { Thickness } \\
(\mathrm{m})\end{array}$ & \begin{tabular}{|l|} 
S-wave \\
Velocity $(\mathrm{m} / \mathrm{s})$ \\
\end{tabular} & \begin{tabular}{|l} 
Density \\
$\left(\mathrm{g} / \mathrm{cm}^{3}\right)$ \\
\end{tabular} & Q-value \\
\hline Table Land & 10 & 250 & 1.7 & 20 \\
\hline $\begin{array}{l}\text { Alluvial Plain } \\
\text { (Sandy } \& \text { Gravelly) }\end{array}$ & 20 & 200 & 1.7 & 20 \\
\hline $\begin{array}{l}\text { Lowland in Valley. } \\
8 \text { Gentle Slope }\end{array}$ & 20 & 150 & 1.7 & 20 \\
\hline $\begin{array}{l}\text { Alluvial Plain } \\
\text { (muddy) }\end{array}$ & 40 & 150 & 1.7 & 20 \\
\hline Coastral Plain & 10 & 200 & 1.7 & 20 \\
\hline $\begin{array}{l}\text { Mountainous } \\
\text { District \& Hill }\end{array}$ & 0 & - & - & - \\
\hline
\end{tabular}

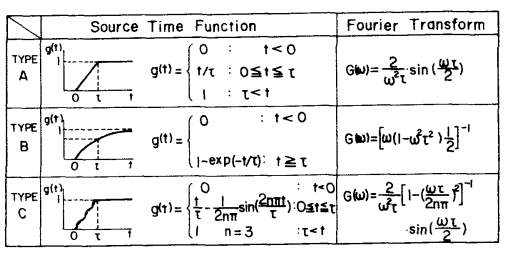

Fig. 12 Source-time fuction of fault model. 

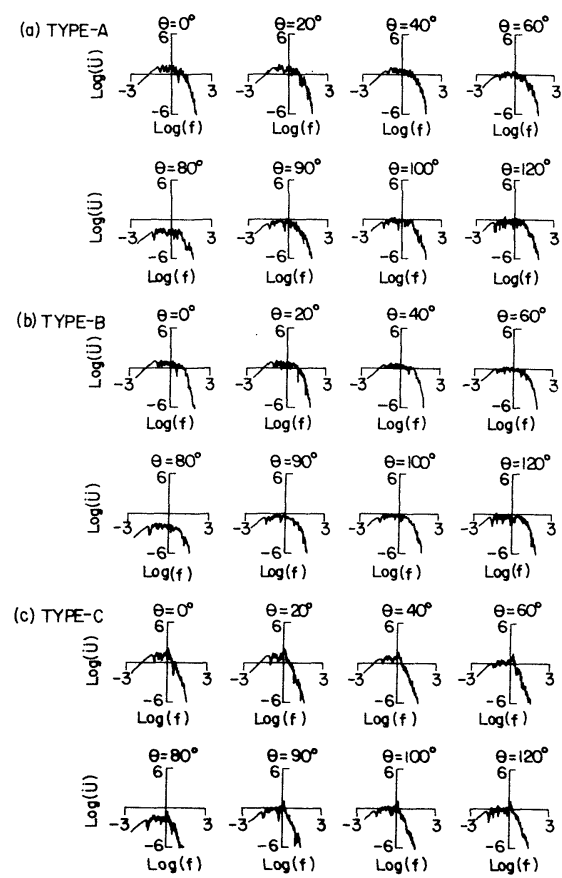

Fig. 13 Fourier spectra at seismological basement calculated by fault model.
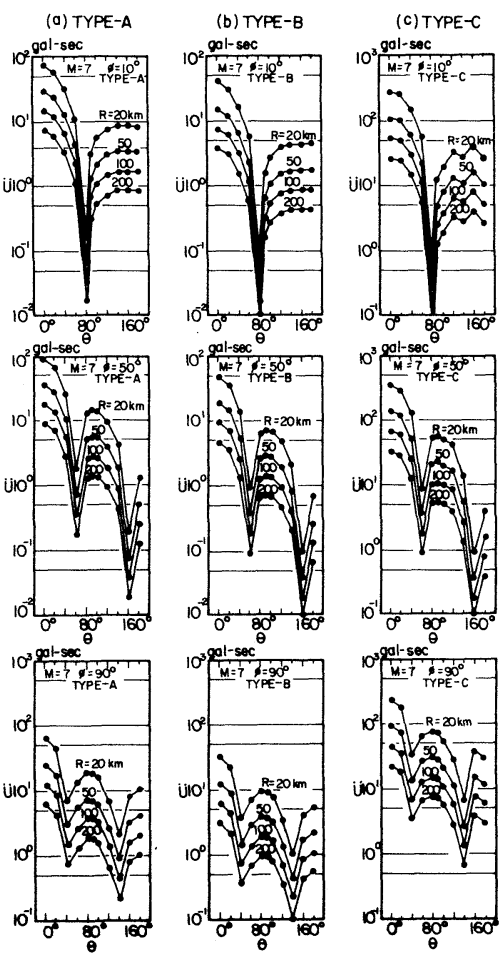

Fig. 14 Variation of maximum spectral amplitude varied with $(\theta, \phi, \gamma)$.

\section{FAULT PARAMETER OF THE ANSEI EDO EARTHQUAKE}

The magnitude of the Ansei Edo Earthquake was evaluated as $M=6.9$ by the area of the seismic intensity $V$ (J.M. A. Intensity Scale). But it is difficult to say the magnitude really $M=6.9$ because there is another case where its magnitude was evaluated as $M=7.2$ by the area of the seismic intensity VI' ${ }^{19}$.

Of course the fault parameters were not clear and it is not possible to specify. Then, in this paper, in order to try an analytical study of the distribution of the seismic intensity, it was assumed that the magnitude of this earthquake had been $M=7.0$ and the parameters were evaluated from the expression varied by the magnitude $M$. The assumed fault parameters are shown in Table 2. Three types of source-time functions shown in Fig. 12 were assumed as the source time function of the fault model. In this paper, it was assumed that the fault plane was perpendicular and the formation of the rupture propagation was a type of strike slip.

In this paper, according to these consideration, the four cases of the hypocenter and location of fault plane as shown in Table 3 and Fig. 15 assumed.

\section{DISTRIBUTION OF SEISMIC INTENSITY BY FAULT MODEL}

In this chapter, using the fault model and the underground structure estimated as mentioned above, the intensity of the seismic ground motion at each site where the seismic intensity was evaluated by the distribution of damage described in Chapter 4 was calculated theoretically and the distribution of the seismic intensity was investigated. For a start, the depth of the bottom basement of Quaternary Strata and the seismological basement which existed directly under the sites where the calculation of the seismic intensity had to be done were estimated by using Fig. 8 and Fig. 7, and then the underground structure model of three Horizontal layered structures (See Fig. 11) were constituted. Also, the total underground 


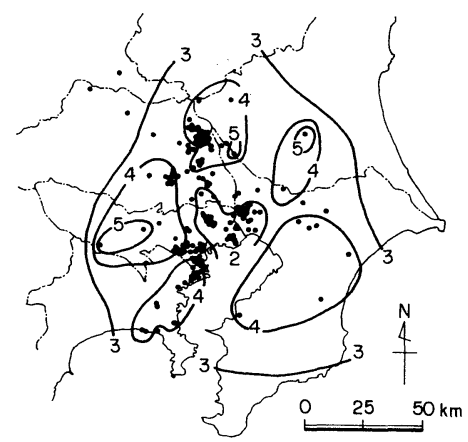

(a) CASE- I, TYPE-B

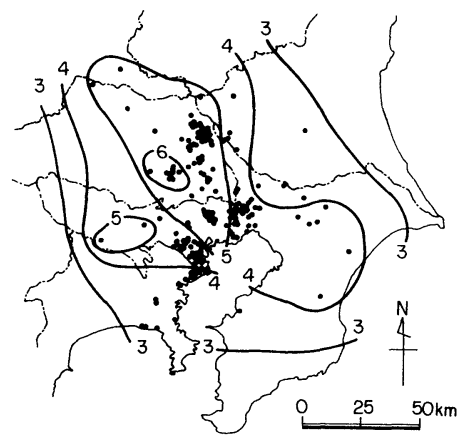

(d) CASE-4, TYPE-B

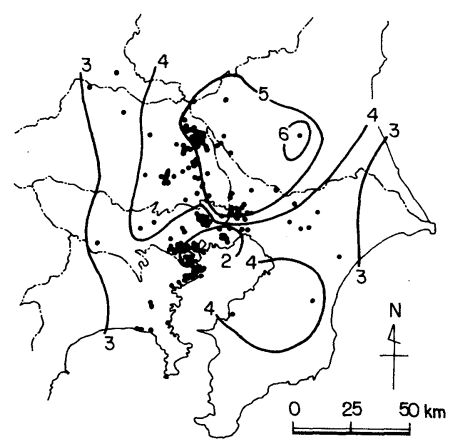

(b) CACE-2, TYPE-B

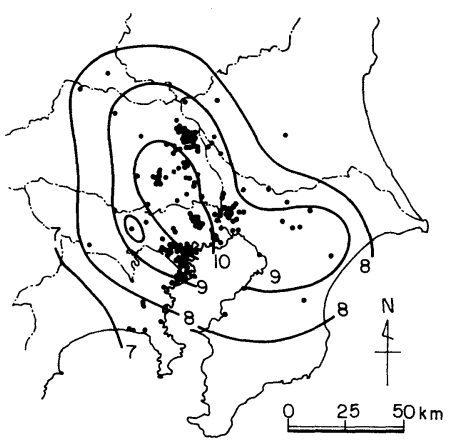

(e) CASE-4, TYPE-C

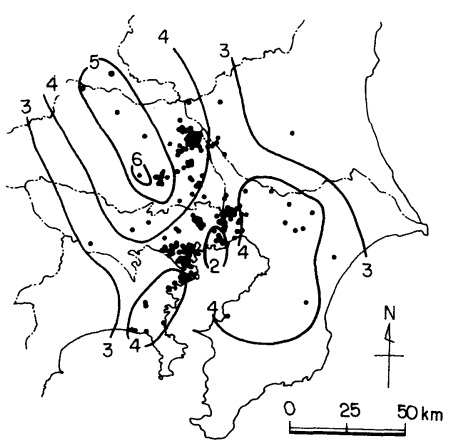

(c) CASE-3, TYPE-B

Fig. 16 Iso-seismal map evaluated by theoretical analysis using fault model.

seismic intensity of this earthquake corresponded very well to the actual distribution of seismic intensity estimated by records of damage distribution.

(3) In the future, it will be necessary to study carefully and improve the estimation process for the fault model and fault plane including the consideration of seismic wave characteristics occurring in the same region in the Kanto District. Particulary, the main items for the improvable and considerable contents are described in the following.

i) Estimation of the location for fault plan

ii) Estimation of the source process of fault

iii) Estimation of the fault parameters

iv) Estimation of the underground structure model

and so on.

\section{ACKNOWLEDGE}

I wish to thank from the bottom of my heart Dr. T. Usami, emeritus professor, Earthquake Research Institute, University of Tokyo and now professor, Shinshu University, for access to the extensive documents and research data for this investigation, and who also gave me much guidance. I express my deep thanks to Dr. T. Mochizuki, professor, Tokyo Metropolitan University, for his advice on this study from the beginning.

\section{REFERENCE}

1) Hiroshi Takahashi : The deep borehole observatories and their contribution to revealing the characteristics of microearthquake activity in the Kanto District, Report of the National Research Center for Disaster Prevention No. 28, pp. 77 83, March, 1982.

2) Keiji Kasahara: Seismicity and plate tectonics in the Kanto District, The Earth Monthly Vol. 7, No. 2, pp. $105 \sim 111,1985$. 
3) Akira Naito : Edo and Edo Castle, Kajima Publishing Association, 1975.

4) Compilation of Tokyo astronomical observatory: Science chronology, Maruzen book company, 1985.

5) Mamoru Sayama : disaster records of the Ansei Edo Earthquake (Vol. 1) (Vol. 2), Tokyo Metropolis, 1973.

6) Toshio Mochizuki, Michio Miyano : On the damage in Tokyo caused by the Ansei Edo, 1855 and the Great Kanto Earthquake, 1923, Transactions of the Architectural Institute of Japan No. 256, pp. 47 56, June 1977.

7) Tatsuo Usami : Investigation of the Edo earthquake of November, 11, 1855 by newly collected old documents, Bulletion of the Earthquake Research Institute, University of Tokyo, Vol.51, Parts 3-4, pp. 209 230, 1976.

8) Yasuo Masai : Map on the land utilization in Edo circa 1860, Japan International Map Socety, Vol. 13, No. 1, 1975.

9) Intensive drawing map of Edo (The second volume), Chuokoron Art Publishing Company, 1975.

10) Japanese Topography Series : Newly edited topography of Musashi, Yuzankaku, 1978.

11) Disaster Mitigation Conference of Tokyo Metropolis : Investigation of the earthquakes of Tokyo vicinity (part 4), Tokyo Metropolice.

12) Toshihiro Kakimi et al. : Neotectonic Map Tokyo, Geological Survey of Japan, 1978.

13) Kazuo Seo, Hiroyoshi Kobayashi: On the seismic prospecting in the Southwestern part of the Tokyo Metropolitan area-Underground structure along the line stations from YUMENOSHIMA, Tokyo to ENOSHIMA, Kanagawa-, Journal of the Seismological Society of Japan ZISIN, second series, Vol. 33, pp. 23 36, 1980.

14) Takashi Tada: Structure of the basement and Gravity Anomaly in the Kanto Plain (1)-Depth distribution of the basement-, Journal of the Seismological Society of Japan ZISIN, second series, Vol. 35, pp.607 617, 1982.

15) Koji Ono: Thea earth crust and Active fault in the plain, symposium on the foreknowledge of earthquakes 1976 in the capital regions, 1984 .

16) Haskell, N. A. : Total energy and energy spectrum density of elastic wave radiation from propagating fault, B. S. S. A., Vol.54, pp. 1811 1841, 1976.

17) Haskell, N. A. : Elastic displacement in the near field of a propagating fault, B. S. S. A., Vol. 59, 1969.

18) Savage, J. G. : Relation of corner frequency to fault dimensions, J. of Geophys. Recearch, Vol.77, pp. 3788 3795, 1972.

19) Tatsuo Usami : Collection of the Historical Earthquake in Japan, University of Tokyo Press, 1981.

(Received May 30 1987) 